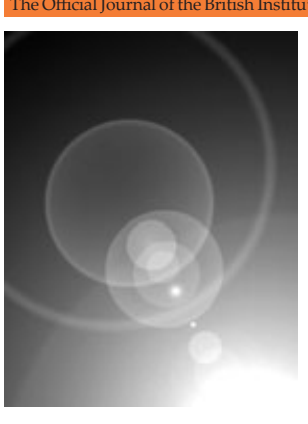

OR I G I N A L ART I C LE

\title{
How we like to live when we have the chance
}

Marthese Deguara, Omar Jelassi, Brian Micallef and Anne-Marie Callus National Commission Persons with Disability, Bugeia Institute, Braille Street, Venera, SVR 1619, Malta (E-mail: amcallus@knpd.org)

\section{Accessible summary}

\section{Summary}

This article has been written by a group of persons with intellectual disability, which is called the Consultative Committee of Persons with Intellectual Disability. This group works in Malta. The article is about how we would like to live. It looks at two things: 'where we would like to live' and 'going out in the community'. This article shows the different opinions of persons with intellectual disability about these subjects. The fact that different people have different opinions shows why it is important that service providers talk to us about how we would like to live. We have a right to choose. Other people should not decide for us about what we would like to do in our lives. But it is also important to remember that we need help in our lives and more accessibility so that we can do what we would like to do.

Keywords Empowerment issues, learning (intellectual) disabilities, research

\section{Who we are}

We are members of the Consultative Committee of Persons with Intellectual Disability of the National Commission Per- sons with Disability ${ }^{1}$ in Malta. This Committee was set up in 2007 (KNPD 2008). It works in favour of the rights of persons with intellectual disability. During meetings, members have the opportunity to talk about matters that interest

\footnotetext{
${ }^{1}$ www.knpd.org.
} 
them and about persons with intellectual disability in Malta. The Committee is very much like selfadvocacy groups that are found in other countries ${ }^{2}$.

It is made up of the Core Committee and the Full Com-

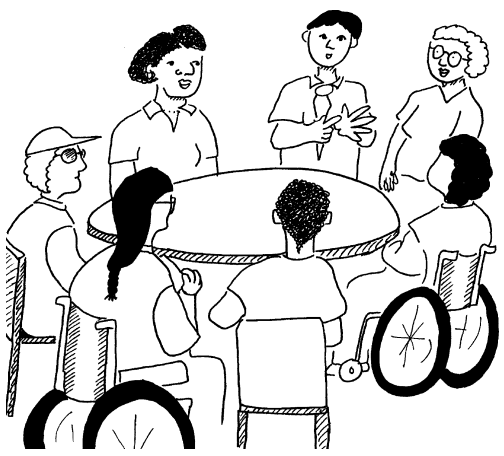
mittee. There are seven members with intellectual disability in the Core Committee and thirty members in the Full Committee. The Core Committee members are chosen by the Full Committee by means of an election held every 2 years. This is our Committee because we control it, with the help that we need ${ }^{3}$.

The Core Committee meets to plan the meetings of the Full Committee. In these meetings, we talk about our concerns. Then, we write reports and present them to the Board of the National Commission Persons with Disability.

\section{How we wrote this article}

This article is based on two research studies that we carried out. One was called 'Where We Would Like to Live', and the other was called 'The Right to Go Out and Be Part of the Community'. The Core Committee prepared the questions that were asked in meetings of the Full Committee. The information that we gathered from the answers was put together in two reports. This article puts together these

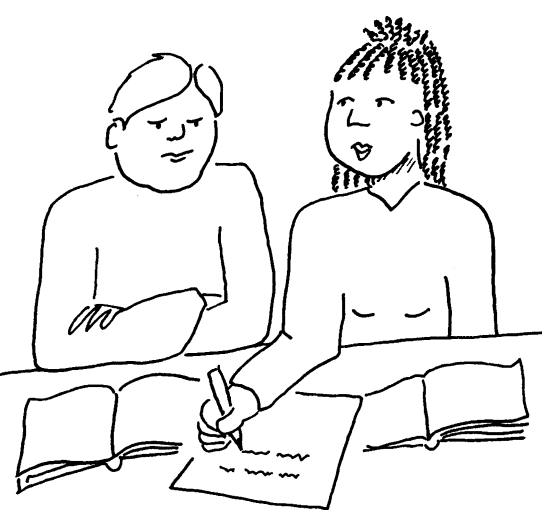
two reports.

Brian, Marthese and Omar are members of the Core Committee. The other members of the Core Committee chose us

${ }^{2}$ Dybwad \& Bersani (1996), Goodley (2000) and Sutcliffe \& Simons (1993) provide more information about the history of selfadvocacy.

${ }^{3}$ For more about the support given by nondisabled people in selfadvocacy groups, see Bramley \& Elkins (1988), Chapman (2005) and Cone (2001). to write this article. Anne-Marie is a support member of the Core Committee and of the Full Committee. In the Core Committee meetings, she helps us write the questions that we then ask in the Full Committee meetings. For the two reports on which this article is based, we chose the subjects ourselves. Then, Anne-Marie helped us think about the type of questions to ask the Full Committee members, and we wrote these down. During the Full Committee meeting, we asked the questions and Anne-Marie helped us write the answers. She also helped us write the reports. We said what we wanted to put down in the reports, and she helped us write out the sentences and put the reports together. She then helped us write this article too in the same way. At the end, she asked us questions that helped us think about what we had learnt from the article. Then, we found pictures, and she helped us find references for the article. She then translated it from Maltese into English. There are many other persons with intellectual disability who have written articles like this ${ }^{4}$.

\section{Where we would like to live}

In the Full Committee meetings, when we talked about where we would like to live, we first looked at what the United Convention on the Rights of Persons with Disabilities (UN 2006) says on the right to choose where to live and the right to live and participate in the community.

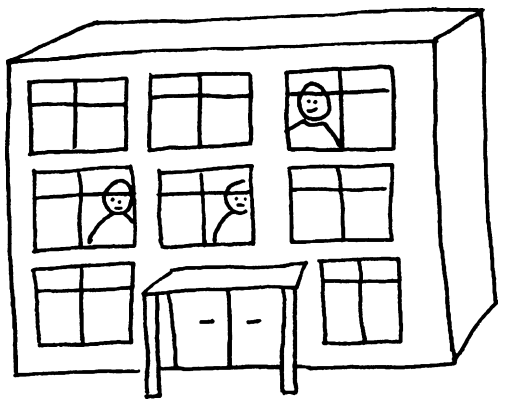

We agree that we should choose where to live. Different people would like to live in different places. These are the places that the Consultative Committee members mentioned:

1. with my family.

2. on my own.

3. with my teacher.

4. with my best friends.

5. with more people.

6. in a flat.

7. in a central place with good public transport connections.

8. Some people would like to live in a house with not more than four persons with intellectual disability.

${ }^{4}$ See for example, Traustadóttir \& Johnson (2000) and Walmsley \& Johnson (2003). 


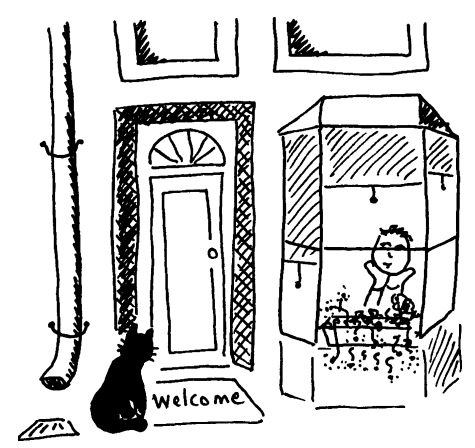

9. Some would like to live in a group with not more than 12 persons with intellectual disability.

10. Some would not like to live with more people because it can be confusing and you do not manage to have your say.

11. Some would like to choose themselves who to live with.

12. Some would like others to help them make the choice because they do not know who to choose.

We do not think that it is right that some people live in a hospital when they can live in a house.

As different people have different wishes, it is important that those who run homes for persons with intellectual disability speak to us and let us decide. They should not decide who we live with.

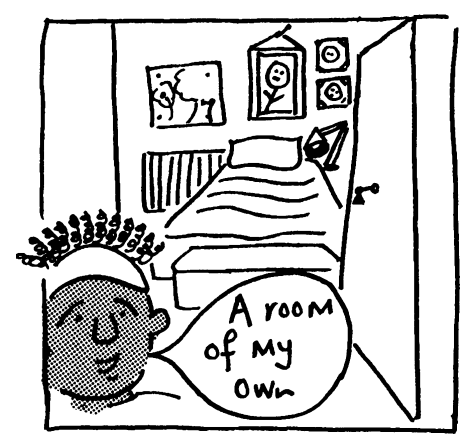

We need help in our everyday life. There are some daily activities that we find difficult. Different people need help in these things:

1. to go out.

2. to go shopping.

3. to cook.

4. to take care of the house.

5. to take care of ourselves.

6. if someone makes fun of us.

Not everyone needs help in the same things. Some people need much help and others need a little. Some people need help in activities that they can learn to do on their own. We would like to go on learning these things.
We need more support workers to work with us. If there are not enough support workers, we cannot always do the things we would like to do.

Support workers should always show us respect and do their work well. We do not want people who do not do their work well. Support workers should get to know well the persons with intellectual disability they work with.

To be able to choose where to live, we also need these things:

1. Our families should agree with us and our wishes.

2. We need money.

3. The government should help us. They should use empty houses so that we can live in them.

4. We need a good public transport service.

In this way, we can lead independent lives. This means that we have the help we need to do the things we would like to do 5 .

If we can live where we would like to live, our parents will no longer worry about what will happen to us when they can no longer take care of us.

\section{Going out in the community}

In the meetings of the Full Committee, we also talked about going out in the community. We looked at what the United Convention on the Rights of Persons with Disabilities (UN 2006) says on the right tolive and participate in the community.

We like going out to different places:

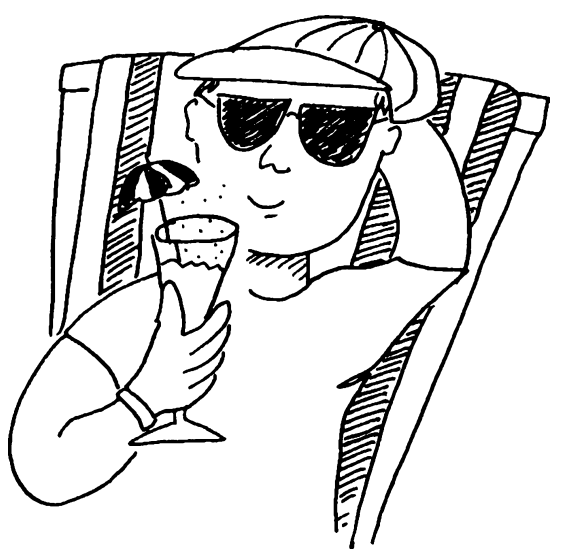

1. by the sea.

2. shopping.

3. eating out.

4. to the theatre and the cinema.

5. walking in the countryside.

6. doing sport.

7. weekend breaks.

8. parties and discos.

9. going abroad.

${ }^{5}$ Many disabled people say this (Barnes \& Mercer (2006)and Thomas (2007)). 
Many of us would like to meet more people. We would like to have more friends. We need more support workers.

It is important that transport and the places we go to are accessible.

We would also like to meet people from other countries. Some of us prefer to stay at home.

People who go out with us should be people who care about us and understand us, and not people who make fun of us, take decisions for us or do not take any notice of us $^{6}$. It is important that we are accepted. It is also important that we behave well with other people.

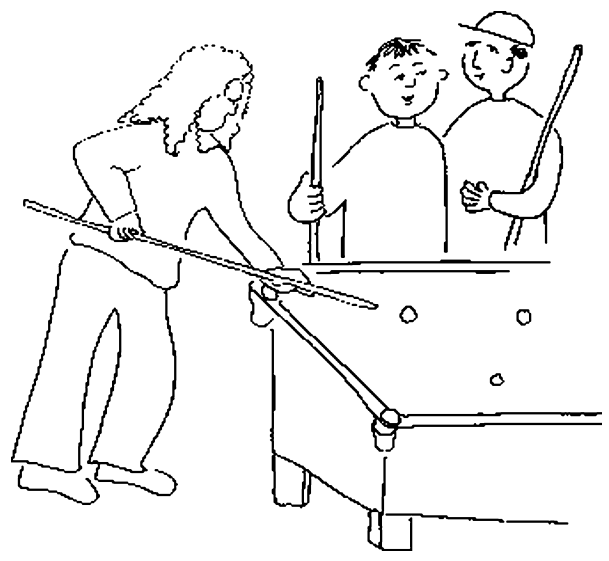

To be able to go out in the community we need these things:

1. phoning up our friends to decide on an outing.

2. enough money and knowing how to spend it well.

3. choosing where to go.

4. having self-confidence. We do not always need friends to go out. Sometimes we can go out on our own.

We like taking part in public activities that are held in Malta. But we also enjoy activities that are organised just for us.

Many of us agree that we feel more independent when we go out than when we stay at home because you need to know where you are going and because you have to be ready on time and check bus times yourself. We have a new bus service in Malta. We hope that this will help us

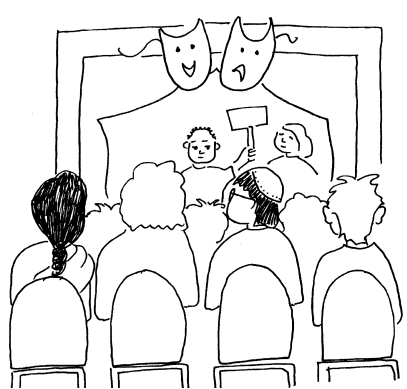
go out more.

Some people feel more independent when they go out on their own. They can spend some time on their own. Others feel more independent when they go out with friends or when they go abroad.

${ }^{6}$ Dearden-Phillips \& Fountain (2005) and Hoole \& Morgan (2011) talk about how we should be involved in the services that we use.

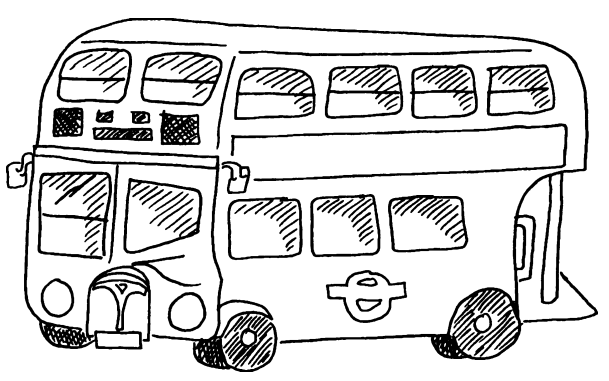

These are the people we like to go out with:

1. Some of us prefer to go out with friends than with family because they are no longer children.

2. Some prefer to go out with parents or relatives.

3. Some people do not go out because they do not have friends.

4. Some people do not go out on their own because they might get lost.

5. Some people go out with their workmates.

6. Some people like to go with friends from their day centre.

There are people who can help us go out more:

1. staff and volunteers.

2. friends.

3. family members.

4. some people, like the hairdresser, help us because we look smart when we go out.

We can go out, but society needs to help us to be able to go out more and be more accepted. ${ }^{7}$

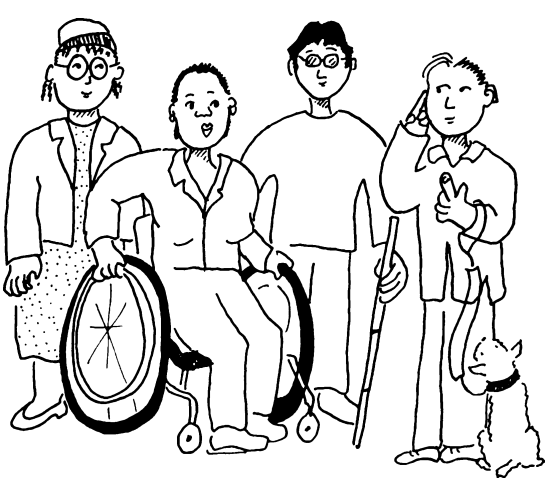

Some people like to go out only with persons with intellectual disability. This is because others make fun of us and do not treat us well. But it is important to distinguish between those people who help us and those who do not.

Some people do not say they have a disability because they are afraid someone will make fun of them.

Some of us like going out both with different persons, persons with intellectual disability and with others too.

${ }^{7}$ Philo (2005) and Waldron (2010) show how we can be left out of the community that we live in. 
We think that it is better to go out with both and not limit yourself to persons with intellectual disability only.

\section{What we learnt from these reports}

We have learnt many things by doing the research and writing these two reports. One of the most important things is that persons with intellectual disability have the right to do the same things as everyone else. But we also have the right to do different things because not everyone likes the same things. Different people with intellectual disability have different preferences. This happens in all aspects of life. This means that no one should decide what we prefer. We should decide ourselves.

For us to be able to decide for ourselves, those who work with us should listen to us and talk to us. We also need more support workers so that we can act on our choices. But this is not enough. To be able to live as we would like to, there need to be more accessible places and services. We also need more money.

Some of us also need help to be able to take care of the money. Most of us need help in our daily lives, but not everyone needs help in the same things. Some of us would do more things on our own if someone teaches us.

Finally, it is important that other people look at us in a positive way. People should not pity us, be afraid of us or ignore us. This is because we want to be a part of our community because we should not be on our own. In this way, other people will get to know us better and learn that we are like everyone else.

Pictures from CHANGE Picture Bank (http://www. changepeople.co.uk).

\section{References}

Barnes C. \& Mercer G., eds. 2006. Independent futures: creating user-led disability services in a disabling society. Bristol: Policy Press.
Bramley J. \& Elkins J. (1988) Some issues in the development of self-advocacy groups among people with intellectual disabilities. Australia and New Zealand Journal of Developmental Disabilities, 14: 147-57.

Chapman R. 2005. The role of the self-advocacy support-worker in UK People First groups: developing inclusive research. Ph.D. thesis. Mitton Keynes: Open University.

Cone A. (2001) Self-reported training needs and training issues of advisors to self-advocacy groups for people with mental retardation. Ment Retard, 39: 1-10.

Dearden-Phillips C. \& Fountain R. (2005) Real power? An examination of the involvement of people with learning difficulties in strategic development in Cambridgeshire $\mathrm{Br} \mathrm{J}$ Learn Disabil, 33: 200-4.

Dybwad G., Bersani H., eds. 1996. New voices: self-advocacy by people with disabilities. Cambridge, MA: Brookline Books.

Goodley D. 2000. Self-advocacy in the lives of people with learning difficulties. Buckingham: Open University Press.

Hoole L. \& Morgan S. (2011) It s only right that we get involved': service-user perspectives on involvement in learning disability services. Br J Learn Disabil, 39: 5-10.

KNPD. 2008. Rapport ta' idma 2007. St Venera, Malta: Kummissjoni Nazzjonali Persuni B'Dizabilità. (Accessed 17th June 2011). Available from http://www.knpd.org.

Philo C. (2005) Introduction to Theme Section on Geographies of Intellectual Disability: 'outside the participatory mainstream'? Health Place, 11: 77-85.

Sutcliffe J. \& Simons K. 1993. Self-advocacy and adults with learning difficulties: contexts and debates. Leicester: National Institute of Adult Continuing Education in association with Open University Press.

Thomas C. 2007. Sociologies of disability and illness: contested ideas in disability studies and medical sociology. Basingstoke: Palgrave.

Traustadóttir R., Johnson K., eds. 2000. Women with intellectual disabilities: finding a place in the world. London: Jessica Kingsley.

UN. 2006. Convention on the rights of persons with disabilities and optional protocol. [Accessed 17th June 2011]. Available from http://www.un.org/disabilities/ documents/convention/ convotprot-e/pdf.

Waldron L. (2010) In the community but still alone - the invisible wall between them and us. Commu Liv, 23: 16-8.

Walmsley J. \& Johnson K. 2003. Inclusive research with people with learning disabilities: past, present and future. London: Jessica Kingsley. 